\title{
FurRow IRRIGATION System Design fOR Clay SoIls in ARID Regions
}

\author{
A. A. Eldeiry, L. A. Garcia, A. S. A. El-Zaher, M. El-Sherbini Kiwan
}

\begin{abstract}
This article presents an accurate and simplified method for designing a furrow irrigation system that would be useful in arid regions with clay soils. Field experiments were conducted at a site in Egypt where cotton is grown in clay soils. The site is usually irrigated every 10 days and follows a three-turn crop rotation. Several parameters were measured including furrow geometry, slope, width, length, infiltration characteristics, advance time, cut-off time, depletion time, and recession time. A volume balance model was applied to simulate water flow in the furrow system, and the results were compared to those obtained from the field measurements. This study shows that a volume balance model can be satisfactorily applied to clay soils, and the length of the furrow and its inlet inflow are the main factors affecting application efficiency. Further, this study indicates that in order to obtain high application efficiencies, furrow inflow rates must increase with longer furrow lengths.
\end{abstract}

Keywords. Furrow geometry, Irrigation system design, Irrigation efficiency, Infiltration characteristics.

I rrigators face intense competition for limited water resources from other sectors of economic activity (Zerihun et al., 1999). Therefore, irrigation system designers must find designs that maximize benefits and minimize water use. Irrigation furrow design should consider constraints in available land area and local conditions when trying to achieve improved irrigation efficiencies.

Almost $25 \%$ of the total cultivated lands in the world are irrigated (Van Vuren and Mastenbrock, 2000). The majority of this land is irrigated using surface methods. Surface irrigation systems have some advantages such as lower capital and operating costs, simplicity of maintenance, and ability to use unskilled labor. Improvements in surface irrigation methods including automation, cutback, and surge irrigation have further increased their appeal. Furrow irrigation is the most common type of surface irrigation, but in most cases the design of furrow systems is not optimal for water use in arid locations with unique infiltration characteristics, such as those present with clay soils. Furrow design parameters are often chosen with limited or no analysis of unique local conditions. There is a need for basic parameters that can be easily applied to furrow irrigation system design so that systems can be optimized for local conditions.

Optimizing the design of furrow irrigation systems has been investigated by a number of researchers. For example, Reddy and Clyma (1981a, b) applied Kelly's cutting-plane algorithm to solve the border and furrow irrigation optimal design problem. They found that the main constraint on furrow irrigation efficiency is that a significant amount of

Article was submitted for review in April 2004; approved for publication by the Soil \& Water Division of ASAE in January 2005.

The authors are Ahmed A. Eldeiry, Graduate Student, Luis A. Garcia, Associate Professor, Department of Civil Engineering, Colorado State University, Fort Collins, Colorado; Ahmed Samy A. El-Zaher, Professor, and Mohammed El-Sherbini Kiwan, Professor, Irrigation and Hydraulics Department, Faculty of Engineering, Cairo University, Cairo, Egypt. Corresponding author: Luis A. Garcia, Department of Civil Engineering, Mail Stop 1372, Colorado State University, Fort Collins, CO 80523; phone: 970-491-5144; fax: 970-491-2293; e-mail: garcia@engr.colostate.edu. water is lost to runoff and deep percolation. These losses depend on the furrow length, furrow inflow, and cut-off times.

Wallender and Rayej (1987) conducted a study in which they maximized profits for a surface irrigation system using both uniform and non-uniform soils while analyzing two design variables (inflow rate and cut-off time). However, deep percolation was not considered in their analysis.

Zerihun et al. (2001) stated that the application efficiency is the primary furrow irrigation system design and management criterion. They presented a detailed analysis of the application efficiency function of a furrow irrigation system. This analysis established that the application efficiency function is a unimodal function of furrow length or furrow inlet flow rate. Optimality conditions were derived. They developed a design and management algorithm that is simple enough to be part of routine design and management exercises and yet rigorous enough to yield near-optimal performance with a minimum calculation effort.

Schwankl et al. (2000) used the zero-inertia furrow irrigation model with specified space solution to investigate the effects of variability in furrow inflow rate and spatial variability in infiltration, geometry, and roughness on end-of-furrow advance, average infiltrated depth, and Christiansen's distribution uniformities. They used extensive infiltration, geometry, and roughness field data as input to the zero-inertia model. They performed simulations on a single furrow as well as field-wide. Variable furrow inflow was incorporated into the field-wide analysis. They evaluated model simulations to determine the importance to irrigation performance of variability in each input variable. Their results indicated that variability of furrow physical characteristics, in decreasing order of their relative impact on furrow irrigation performance, were: furrow inflow rate, infiltration, geometry, and roughness. For a field with highly variable soil and infiltration characteristics, spatially varying infiltration may have a greater impact than variable furrow inflow on irrigation performance.

El-Dine and Hosny(2000) studied the performance of surge and continuous furrow irrigation. Their experiment 
took place on two farms located in New Mexico, cultivated with beans and alfalfa and having different types of soil. Each farm was divided into two parts, one using surge irrigation and the other using continuous irrigation. Their results indicate that surge flow provides the desired crop water requirement while using almost $40 \%$ less water and improving the distribution uniformity and application efficiency of irrigation to about $90 \%$.

Kang et al. (2000) conducted a field experiment on soil water distribution, irrigation water advance and uniformity, yield production and water use efficiency with a new irrigation method for maize in an arid area with seasonal rainfall. Irrigation was applied through furrows in three ways: alternate furrow irrigation (AFI), fixed furrow irrigation (FFI), and conventional furrow irrigation (CFI). For alternate furrow irrigation one of the two neighboring furrows was alternately irrigated during consecutive watering. For FFI, irrigation was fixed to one of the two neighboring furrows. Every furrow was irrigated during each watering for furrows using CFI. Each irrigation method was further divided into three treatments using different irrigation amounts. Results showed that the soil water contents in the two neighboring furrows of AFI remained different until the next irrigation with a higher water content in the previously irrigated furrow. Infiltration in CFI was deeper than that in AFI and FFI. The time of water advance did not differ among the three methods at all distances monitored. The measure of the uniformity of irrigation water distribution showed no decrease in AFI and FFI, although irrigation water use was smaller than in CFI. Root development was significantly enhanced by AFI treatment. The most surprising result was that AFI maintained high grain yield with up to a $50 \%$ reduction in irrigation amount, while FFI and CFI treatments all showed a substantial decrease in yield with reduced irrigation.

Valiantzas (2001a, b) stated that by using an explicit time of advance equation the furrow irrigation design is formulated as an optimization (cost minimization) problem. For a specified furrow length, the objective function to be minimized becomes the total inflow water volume, independent of the water and labor cost coefficients. The only design variable to be optimized is the furrow inlet rate. They derived a simple algebraic equation to calculate the inflow rate directed at minimizing costs. They tested the predictive quality of the suggested equation by systematically comparing it with the output of the zero-inertia numerical model. The method was extended for furrow design considering the furrow length as a design variable. The values of optimum design variables (number of furrow sets in the lengthwise and widthwise directions) were derived by the proposed simple set of calculations.

They developed a particularly simple equation to calculate the time of advance directly from the furrow distance. The suggested equation has the same simplicity of the SCS (Soil Conservation Service, now Natural Resources Conservation Service) time of the advance equation. Valiantzas (2001a, b) stated that the proposed equation may be sufficient for routine furrow irrigation design application, particularly when considering the great uncertainties of parameters required as inputs to hydrodynamic numerical models and the high level of sophistication associated with the various furrow design optimization techniques. The suggested equation is also the basis for the derivation of a simple equation used for direct optimum-design inflow rate calculation. The equation is derived as an extension of the two small-time, large-time explicit advance time solutions. The equation extended for infiltration functions of any mathematical form. The accuracy of the equation was evaluated by comparing predicted advance rates with observed furrow advance data and a zero-inertia model. In all the cases examined, the proposed equation provided predictions that were in good agreement with field data and the zero-inertia model results.

Furrow cross section is very important in design. Cahoon (1995) stated that it is useful to define a standard shape that represents the furrow cross section. They discussed five geometric shapes that could be used: (1) linear interpolation between successive points; (2) trapezoid symmetric about the furrow center; (3) a least-squares parabola that only considers portions of the furrow in which flow can occur without overtopping the furrow ridge; (4) a sigmoid with the period equal to the furrow spacing and amplitude equal to half the maximum depth; and (5) a least-squares fit triangle. The researchers stated that the shape chosen is likely to depend on furrow conditions and the ultimate reason for defining the cross section.

Soil infiltration also plays an important role in irrigation design efficiency and in the selection of irrigation methods. Infiltration characteristics are highly variable. This high variability has motivated studies on the effects of spatial variability of infiltration rates on surface irrigation system performance (Nielsen et al., 1973; Bautista and Wallender, 1985; Prasher et al., 1997; Childs et al., 1993; Greminger et al., 1985).

This article describes an improved procedure for the design of furrow irrigation systems based on field data from an arid site in Egypt with clay soils. This methodology is useful not only for the design of new furrow systems but also for the evaluation of existing systems in order to improve efficiency.

\section{Materials AND Methods}

There are many models commonly used to design and simulate furrow irrigation systems. The most common approaches include hydrodynamic (characteristic approach Eluorine integration), zero-inertia, kinematic wave, and volume balance models.

In this study, a volume balance model was used that produces accurate results with modest data requirements. Upadhyaya and Raghuwanshi (1999) present a number of mathematical models for surface irrigation developed to simulate the depth of flow, advance time, recession time, infiltrated volume, runoff volume, and deep percolation. These models utilize full hydrodynamic, zero-inertia, and kinematic wave methods for furrow irrigation design. Two approaches can be used to implement these models. The first approach is to use the principle of mass conservation (volume balance) and to assume a surface storage shape factor that replaces the momentum equation. The second approach is to use the conservation of mass and energy principle, also known as the Saint-Venant equation. Since the full hydrodynamic approach requires tedious numerical solutions, very intense computational efforts, and extensive data sets, it is difficult and expensive to run for a wide range of field 
conditions. Additional models were evaluated, and the volume balance model was chosen for this study since it has proven to be accurate; the data it requires can be readily collected; and it relies on few assumptions.

The volume balance model assumes that at any time, $t$, water entering the field will progress a distance, $X$, toward the lower end of the field. The furrow inflow at the inlet of the field, $Q_{o}$, is assumed steady, so that at time, $t$, the product of $Q_{o}$ and $t$ equals the volume of water on the soil surface, $V_{y}(t)$, plus the volume infiltrated, $V_{z}(t)$, which are both time dependent.

$$
\begin{gathered}
Q_{o} t=V(t)+V_{z}(t) \\
V_{y}(t)=\sigma_{y} A_{o} X=\bar{A} X \\
V z(t)=\int_{0}^{x} z(s, t) d s W_{f}
\end{gathered}
$$

where $\bar{A}$ is the average area of the furrow shape, $W_{f}$ is the furrow width, $A_{o}$ is the cross-sectional flow area at the field inlet, $\sigma_{\mathrm{y}}$ is the surface shape parameter, $z(s, t)$ is the infiltrated volume per unit length over the advance length, and $s$ is the distance in which the advancing front reaches it.

$$
Q_{o} t=\sigma_{y} A_{o} X+\sigma_{z} X W_{f}
$$

where $\sigma_{z}$ is the the sub-surface shape parameter.

In order to solve this equation the volume balance model uses the following two assumptions:

1) The trajectory of the advance of the waterfront in a furrow or border can be described as a simple power function:

$$
X=P\left(t_{s}\right)^{r}
$$

where $X$ is the distance that the front has advanced at time $t_{s}$, and $r$, and $P$ are empirically fitted parameters.

2) The infiltration function has a Kostiakov-Lewis characteristic form (Walker and Skogerboe, 1987):

$$
Z=k \tau^{a}+f_{o} \tau
$$

where $Z$ is the volume of infiltrated water per unit length, $\tau$ is the opportunity time, $f_{o}$ is the basic intake rate in units of volume per unit length per unit time, and $k$ and $a$ are empirically fitted parameters.

Utilizing these two assumptions in the Lewis-Milne equation, the volume balance model can be written as follows (Walker and Skogerboe, 1987):

$$
Q_{o} t_{s}=\sigma y A_{o} X+\sigma z k t_{s}^{a} X W_{f}+\frac{f_{o} t_{s} X W_{f}}{(1+r)}
$$

where

$$
\begin{gathered}
\sigma_{z}=\frac{[a+r(1-a)+1]}{(1+a)(1+r)} \\
\sigma_{y}=\frac{\bar{A}}{A_{o}}
\end{gathered}
$$

where $\sigma_{z}$ is the subsurface water profile shape factor and $\sigma_{y}$ is the surface water profile shape factor.
The design procedure requires the determination of the furrow geometry factors, the advance time, and the application efficiency. These parameters will be discussed here.

The furrow geometry data collected was used to derive the relationship between the depth of water in the furrow and the corresponding top width. Equation 10 was used to approximate this relationship. The parameters $\alpha_{1}, \alpha_{2}$ can be obtained using data fitting for the equation:

$$
B=\alpha_{1} \mathrm{y}^{\alpha_{2}}
$$

where $B$ is top width of water in the furrow, $y$ is the depth of water in the furrow, $\alpha_{1}$ and $\alpha_{2}$ are the top width factor parameters.

The wetted perimeter factor parameters $\gamma_{1}$ and $\gamma_{2}$ can be obtained from the following relation:

$$
W P=\gamma_{1} \mathrm{y}^{\gamma_{2}}
$$

where WP is the wetted perimeter of the furrow.

Therefore the area shape factor parameters $\sigma_{1}$ and $\sigma_{2}$ can be obtained as follows:

$$
\sigma_{1}=\frac{\alpha_{1}}{\left(\alpha_{2}+1\right)}, \quad \sigma_{2}=\alpha_{2}+1
$$

The cross-sectional flow area at the field inlet, $A_{o}$, can be calculated using the Manning equation as follows:

$$
A_{o}=C_{1}\left[\frac{Q_{o} n}{60 S_{o}^{0.5}}\right]^{C_{2}}
$$

where

$$
C_{2}=\frac{3 \sigma_{2}}{\left(5 \sigma_{2}-2 \gamma_{2}\right)}, \quad C_{1}=\sigma_{1}\left(\frac{\gamma_{1}^{0.67}}{\sigma_{1}^{1.67}}\right)
$$

where $\mathrm{Q}_{\mathrm{o}}$ is the furrow inflow ( $\left.\mathrm{m}^{3} / \mathrm{min}\right), \mathrm{n}$ is the Manning roughness coefficient, and $\mathrm{S}_{\mathrm{O}}$ is the field slope.

From the above equations, the furrow shape parameters were calculated and summarized in table 1 for all furrows used in this study.

Upadhyaya and Raghuwanshi (1999) stated that improving furrow irrigation performance requires parameter information for the advance function. In a furrow event, advance time depends on soil infiltration characteristics, roughness of the soil surface, inflow rate, and furrow slope and shape, whereas the recession time is usually short and negligible for undiked furrows (Fok and Bishop, 1965). The NewtonRaphson procedure can be used to get the advance time using the following equation:

$$
t=t_{s}-\frac{Q_{\mathrm{o}} t_{s}-\sigma_{y} A_{\mathrm{o}} L-\sigma_{z} k t_{s}^{a} L W_{f}-\frac{f_{\mathrm{o}} t_{s} L W_{f}}{(1+r)}}{Q_{\mathrm{o}}-\frac{\sigma_{z} a k W_{f}}{t_{s}(1-a)}-\frac{f_{\mathrm{o}} L W_{f}}{1+r}}
$$

From the above equation, the advance time was calculated for all furrows at eight different points in each furrow.

The application efficiency $(E a)$ is the volume of water needed to fill the required depth of water in the soil divided 
Table 1. Furrow shape parameters.

\begin{tabular}{|c|c|c|c|c|c|c|c|c|c|c|c|}
\hline Furrow & $\alpha_{1}$ & $\alpha_{2}$ & $\sigma_{1}$ & $\sigma_{2}$ & $\gamma_{1}$ & $\gamma_{2}$ & $\sigma_{\mathrm{z}}$ & $\sigma_{\mathrm{y}}$ & $\mathrm{C}_{2}$ & $\mathrm{C}_{1}$ & $A_{o}\left(m^{2}\right)$ \\
\hline 1 & 1.00 & 0.39 & 0.72 & 1.39 & 5.31 & 0.91 & 0.83 & 0.80 & 0.81 & 2.765 & 0.01 \\
\hline 2 & 1.26 & 0.47 & 0.86 & 1.47 & 5.67 & 0.94 & 1.02 & 0.80 & 0.807 & 2.692 & 0.007 \\
\hline 3 & 1.16 & 0.46 & 0.80 & 1.46 & 5.33 & 0.93 & 1.00 & 0.80 & 0.807 & 2.676 & 0.006 \\
\hline 4 & 1.40 & 0.47 & 0.95 & 1.47 & 6.31 & 0.95 & 1.11 & 0.80 & 0.808 & 2.759 & 0.004 \\
\hline 5 & 1.02 & 0.41 & 0.73 & 1.41 & 5.11 & 0.92 & 0.77 & 0.80 & 0.811 & 2.719 & 0.010 \\
\hline 6 & 1.21 & 0.46 & 0.83 & 1.46 & 5.47 & 0.94 & 0.75 & 0.80 & 0.807 & 2.674 & 0.007 \\
\hline 7 & 1.29 & 0.44 & 0.90 & 1.44 & 6.12 & 0.93 & 0.81 & 0.80 & 0.811 & 2.781 & 0.006 \\
\hline 8 & 1.05 & 0.41 & 0.74 & 1.41 & 5.17 & 0.92 & 1.06 & 0.80 & 0.811 & 2.715 & 0.004 \\
\hline 9 & 1.67 & 0.57 & 1.07 & 1.57 & 6.55 & 0.98 & 0.77 & 0.80 & 0.800 & 2.682 & 0.010 \\
\hline 10 & 1.91 & 0.58 & 1.21 & 1.58 & 6.84 & 0.99 & 0.78 & 0.80 & 0.799 & 2.628 & 0.007 \\
\hline 11 & 1.97 & 0.46 & 1.35 & 1.46 & 9.30 & 0.97 & 0.80 & 0.80 & 0.815 & 3.035 & 0.006 \\
\hline 12 & 1.41 & 0.44 & 0.98 & 1.44 & 7.12 & 0.95 & 0.82 & 0.80 & 0.814 & 2.940 & 0.004 \\
\hline 13 & 1.27 & 0.41 & 0.90 & 1.41 & 6.37 & 0.93 & 0.75 & 0.80 & 0.815 & 2.855 & 0.010 \\
\hline 14 & 1.75 & 0.51 & 1.15 & 1.51 & 7.19 & 0.97 & 0.77 & 0.80 & 0.806 & 2.761 & 0.007 \\
\hline 15 & 1.41 & 0.45 & 0.98 & 1.45 & 6.56 & 0.94 & 0.85 & 0.80 & 0.811 & 2.804 & 0.006 \\
\hline 16 & 1.42 & 0.44 & 0.99 & 1.44 & 6.72 & 0.94 & 0.85 & 0.80 & 0.812 & 2.834 & 0.004 \\
\hline Average & 1.39 & 0.46 & 0.95 & 1.46 & 6.32 & 0.94 & 0.86 & 0.80 & 0.809 & 2.770 & 0.007 \\
\hline
\end{tabular}

by the volume of water delivered to the furrow and is calculated using the following equation:

$$
E a=\frac{Z(\text { req }) L W_{f}}{t(\text { co }) Q_{\mathrm{O}}}
$$

where $Z(r e q)$ is the required depth in meters to be filled and $t(c o)$ is the cut-off time in minutes.

A detailed field experiment was implemented to determine the accuracy of the modeling in representing a typical furrow design. The study site was located in an arid location in Egypt's Nile River Valley where there is a critical need for judicial water use and productive agriculture.

A 1-ha study site was chosen in the Bani-Suef district of Egypt along the Nile. The irrigation system used at this site is furrow irrigation with furrow lengths between 10 to $15 \mathrm{~m}$; such short furrow lengths are common in Egypt and are tied to traditional farming practices. Approximately one-sixth of
1 ha of the study site was used to conduct the detailed study described in this article. The experimental site has clay soils, cultivated with cotton and irrigated by a three-turn crop rotation. Several parameters were measured before and during the experiment including the furrow geometry, slope, width, length, infiltration characteristics, advance time, cut-off time, depletion time, furrow inflow, and recession time.

The layout of the experiment area is shown in figure 1. The area consists of four groups of four furrows each. All the furrows have the same width $(0.8 \mathrm{~m})$, and each furrow group has a length of 90,60,30, and $15 \mathrm{~m}$, respectively. A gasoline powered centrifugal pump having a discharge capacity of $4 \mathrm{~m}^{3} / \mathrm{min}$ was used to maintain a constant water level at the head ditch. The head ditch was used to deliver water to each furrow group by sets of pipe siphons. The siphons were chosen in a way that four different furrow inflows for each group of furrows could be applied and measured with

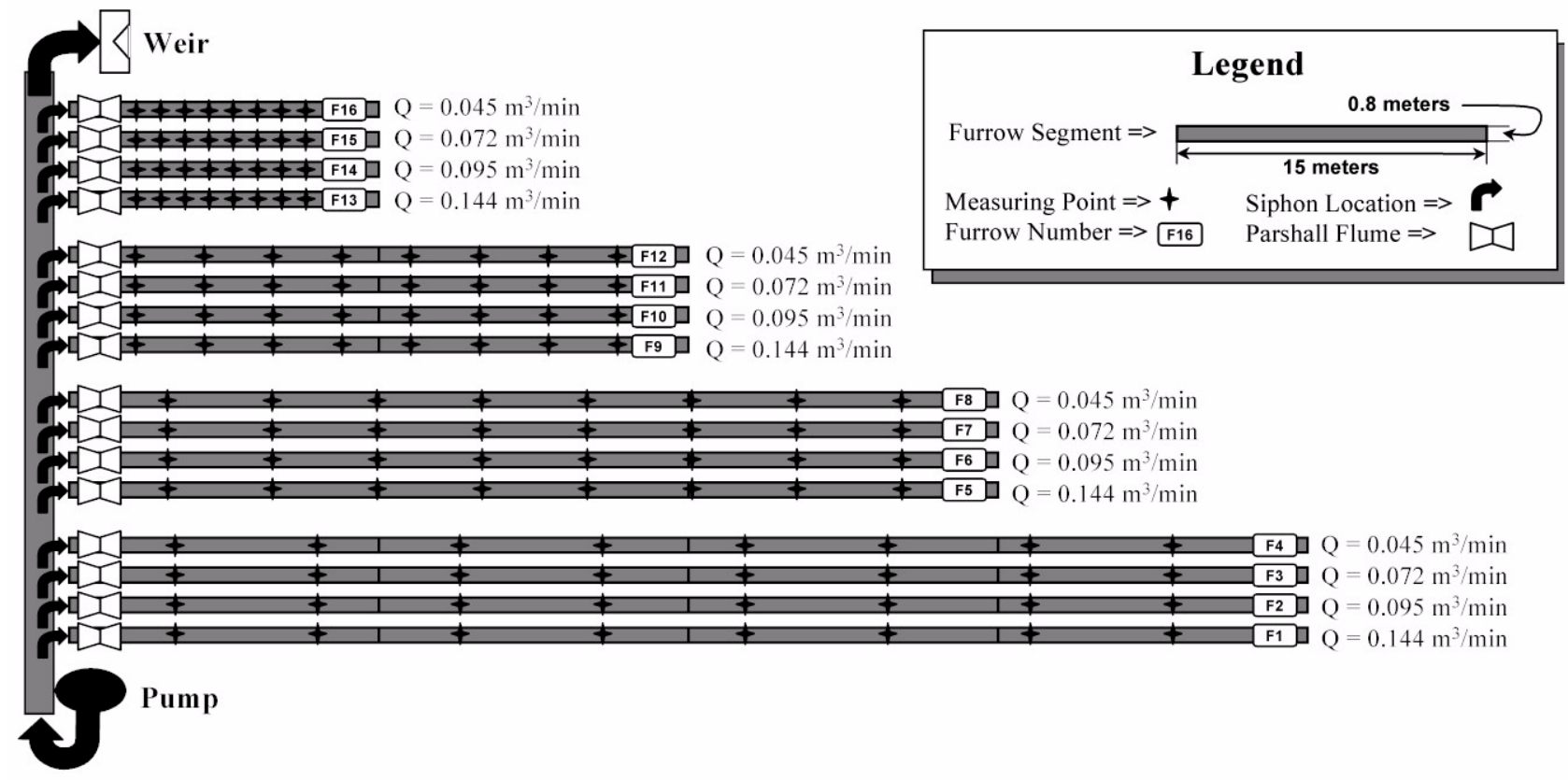

Figure 1. Schematic of the experimental area in Egypt. 
Parshall flumes during irrigation. The measured furrow inflows for the four furrows during irrigation were 0.144 , $0.094,0.072$, and $0.045 \mathrm{~m}^{3} / \mathrm{min}$, respectively. The total measured furrow inflow for each furrow group was $0.355 \mathrm{~m}^{3} / \mathrm{min}$. A weir was constructed at the end of the head ditch to maintain the water level and to deliver the excess water to the rest of the field.

A surveying instrument was used to adjust the level of the land at different locations throughout the furrow lines. The weighted average method was used to calculate an average furrow slope, where each line was divided into sectors and the slope was estimated for each individual sector. Finally, a weight was assumed for each sector and the weighted average slope was estimated to be $0.5 \%$.

A profilometer which is a wooden frame consisting of two horizontal wooden pieces and two vertical legs was used to measure the furrow geometry. Steel rods with constant lengths were fixed in the horizontal pieces of wood through small holes. A drawing paper was fixed behind the rods on the frame. The two vertical legs of the apparatus are placed in a way that the steel rods were plumb and then the steel rods were lowered until they touched the furrow surface. Hence, the shape of the furrow is repeated at the top of the steel rods on the drawing paper and can be traced. The furrow shape was traced four times for each furrow and the average of the four values for each furrow was used. The average for all furrows was calculated to get the overall furrow shape parameters for the model calculations.

The soil basic infiltration $\left(f_{o}\right)$ parameter was measured in the field by using a double ring infiltrometer. The two rings penetrated the soil about $0.2 \mathrm{~m}$. The inner ring has two marks separated by a standard distance of $0.03 \mathrm{~m}$. The time taken for the water to drop from the upper mark to the lower mark was recorded. This procedure was repeated until the time taken for the water level to drop from the first mark to the second mark became the same for at least three consecutive readings.
At each furrow, eight pieces of wood were set into the furrows at equal distances along the furrow length. The travel time of water advancing through each furrow was recorded at each mark. The cutoff time for each furrow was recorded along with the depletion and recession times.

Four siphon diameters, each with different furrow inflow characteristics, were used for each group of furrow lines, and Parshall flumes were used to measure the actual flow. The dimensions for construction of the 1-in. Parshall flumes and the coefficients for the flow calculations were taken from Skogerboe (1969).

\section{RESULTS AND DisCUSSION}

Figure 2 illustrates drawdown versus time and the estimated infiltration rate. Parameter $f_{o}$ was estimated as $0.0005 \mathrm{~m}^{3} / \mathrm{min} / \mathrm{m}$ from the results of the infiltration tests. Therefore, the infiltration function is in the form:

$$
Z=k \tau^{a}+0.0005 \tau
$$

As stated in the model description section, the infiltration function is very important for two reasons. First, the basic infiltration rate is used to determine the advance time of the flow through the furrow length, and this parameter is very sensitive. Second, calculating parameters $k$ and $a$ in the infiltration function depend on the basic infiltration rate and are used later to calculate the advance time.

The model formulation requires several shape factors including top width, area, water depth, and wetted perimeter. These data were measured in the field for all furrows. Regression analysis was used to obtain the shape factor parameters for each furrow. Cross-sectional area parameters were obtained using both the top width and wetted perimeter factors. The same procedures were repeated for each furrow. Figures 3 and 4 were constructed to determine the furrow

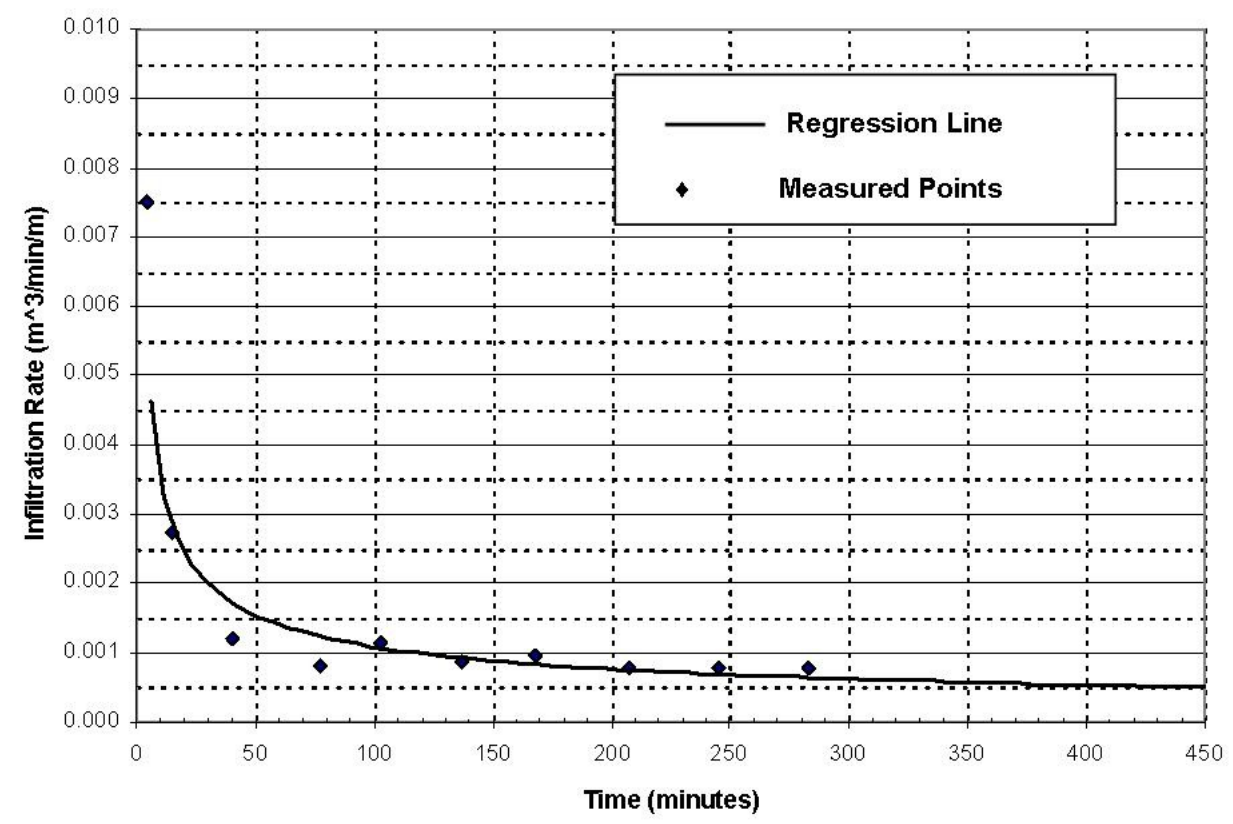

Figure 2. Infiltration rate vs. time for clay soil with measured points and regression curve. 


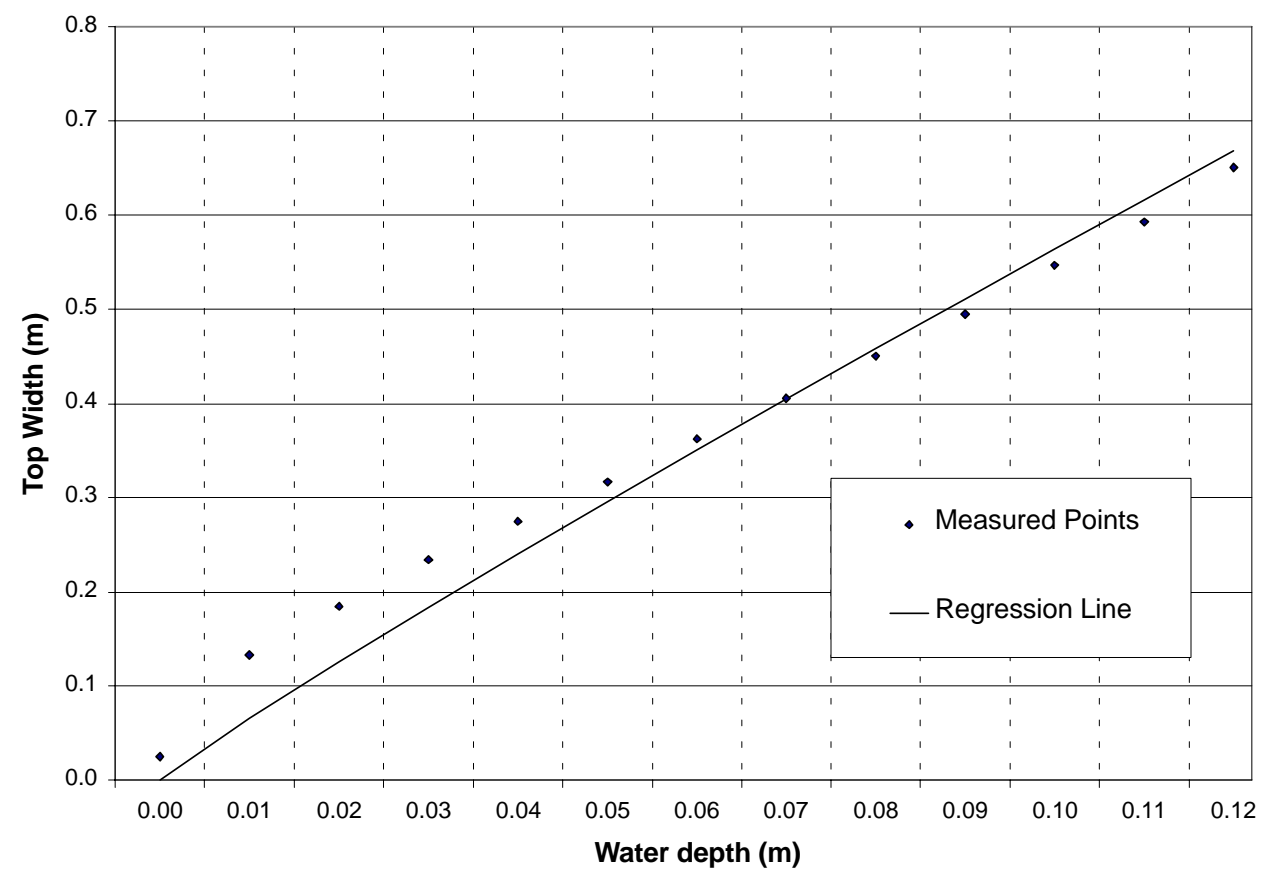

Figure 3. Water depth vs. top width at the measuring points of the furrow.

shape parameters. Figure 3 represents the relation between the water depth and the water top width of the water surface.

Figure 4 represents the relation between the water depth and the wetted perimeter, after fitting the data with a power function we obtained the values of $\gamma_{1}$ and $\gamma_{2}$. Also, the values of $\sigma_{1}$ and $\sigma_{2}$ were obtained from the values of $\alpha_{1}$ and $\alpha_{2}$ as discussed in the model description section.

Furrow shape parameters can significantly affect the value of the calculated advance time. Therefore, furrow shape was measured at eight points along each furrow, and averages of each furrow set were used for model calculations shown in figures 5 and 6 . Furrow shape is highly variable along the length of individual furrows under the best of conditions.
Figures 5 and 6 show a comparison between the measured and calculated advance time using the volume balance model. Furrows are arranged in the figures according to their inflow rate. For example, figure 5 represents furrows with lengths of $90,60,30$, and $15 \mathrm{~m}$ and an inflow rate of $0.045 \mathrm{~m}^{3} / \mathrm{min}$, while figure 6 shows results when using an inflow rate $0.144 \mathrm{~m}^{3} / \mathrm{min}$. Figures 5 and 6 illustrate that the measured readings were close to the model's calculated values with a deviation of 30\% for most advance times. Many of these differences can be attributed to variability in field parameters such as slope and shape of furrows, soil roughness, and soil moisture conditions.

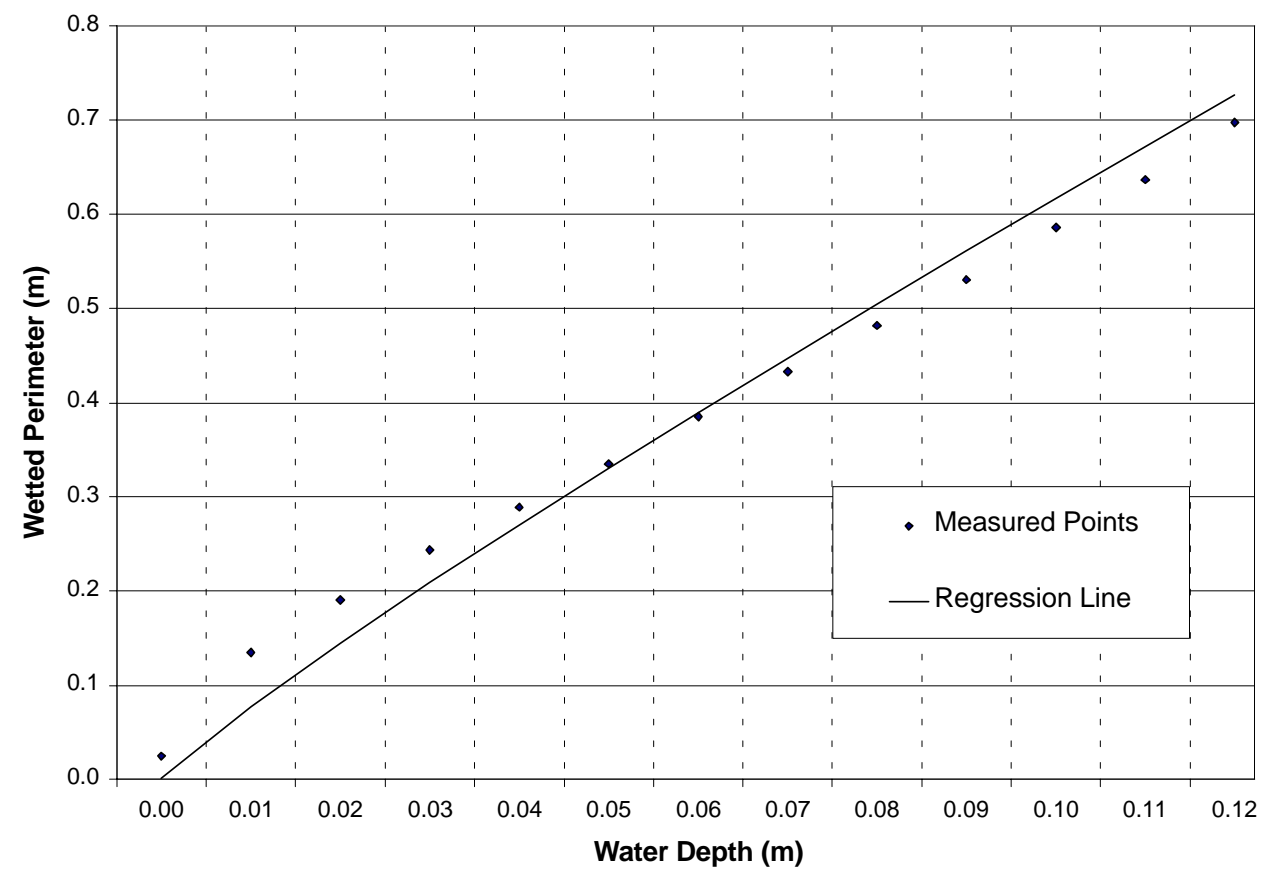

Figure 4. Water depth vs. wetted perimeter at the measuring points of the furrow. 


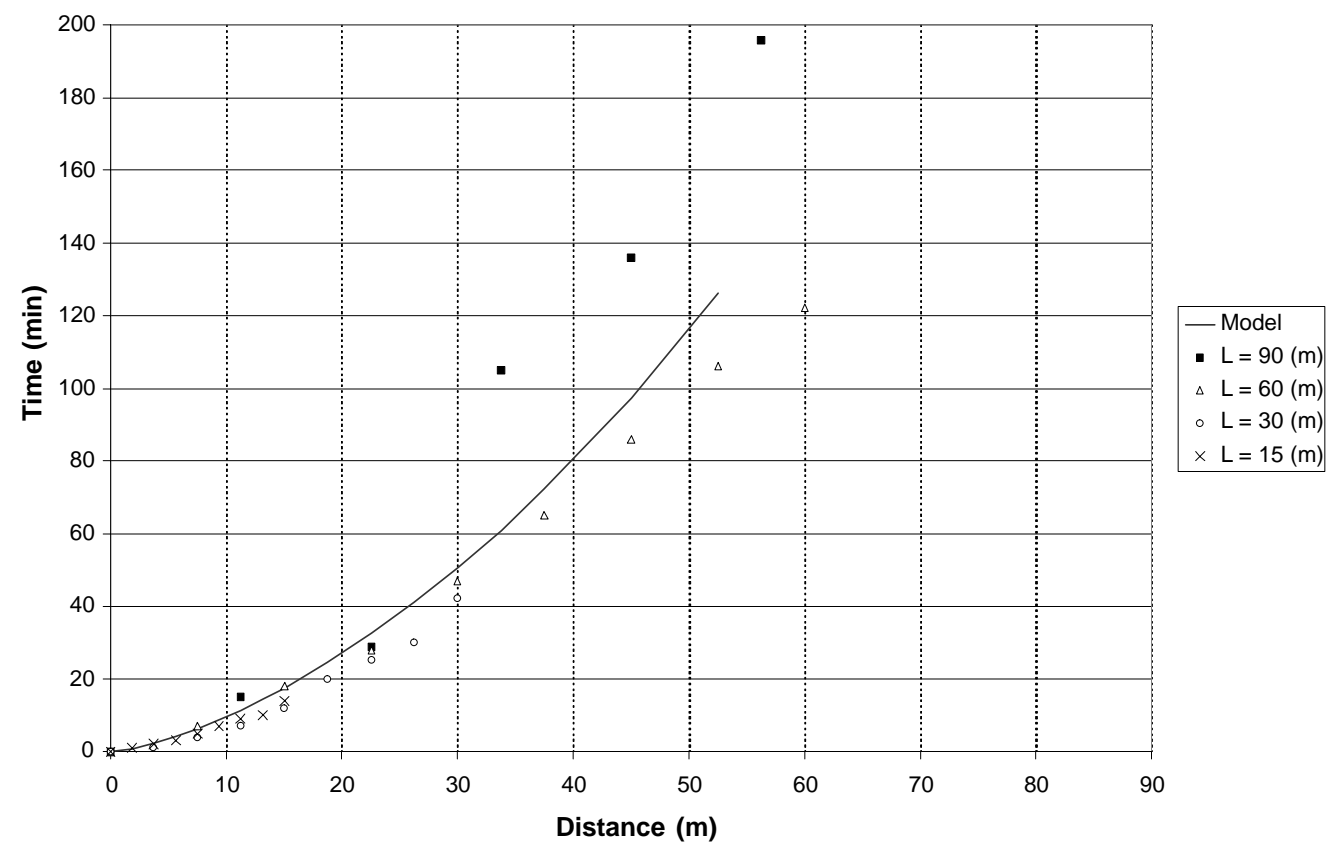

Figure 5. Distance vs. advance time for $Q=0.045 \mathrm{~m}^{3} / \mathrm{min}$ of the measured points and the model prediction.

As can be seen from figure 5 , the model was not able to calculate an advance time for furrow lengths greater than $52.5 \mathrm{~m}$. For practical applications, this limitation is reasonable since the minimum inflow used in this study $\left(0.045 \mathrm{~m}^{3} / \mathrm{min}\right)$ is insufficient to reach the end of the furrow with reasonable losses in infiltration. However with small furrow lengths (i.e. 15 and $30 \mathrm{~m}$ ), the measured values are very close to the calculated values. Alternatively, figure 6 illustrates that at higher inflows there is agreement between the model and measured values for furrow lengths of 60 and $90 \mathrm{~m}$ but not for 15 and $30 \mathrm{~m}$. These results demonstrate that the model is performing well in the practical design range of most furrow systems (i.e. where the inflow amounts are correctly paired with furrow lengths).

Figure 7 represents the relationship between the furrow length (from near 0 to $500 \mathrm{~m}$ ) and application efficiency for selected furrows used for the model calculations. Figure 7 illustrates that high efficiencies can be achieved for small furrow lengths with relatively low furrow inflows, and alternatively, larger furrow inflows are needed as furrow length increases to obtain high efficiencies. Figure 7 can be used to determine where this change in trend occurs in order to achieve an optimal furrow length given a furrow inflow.

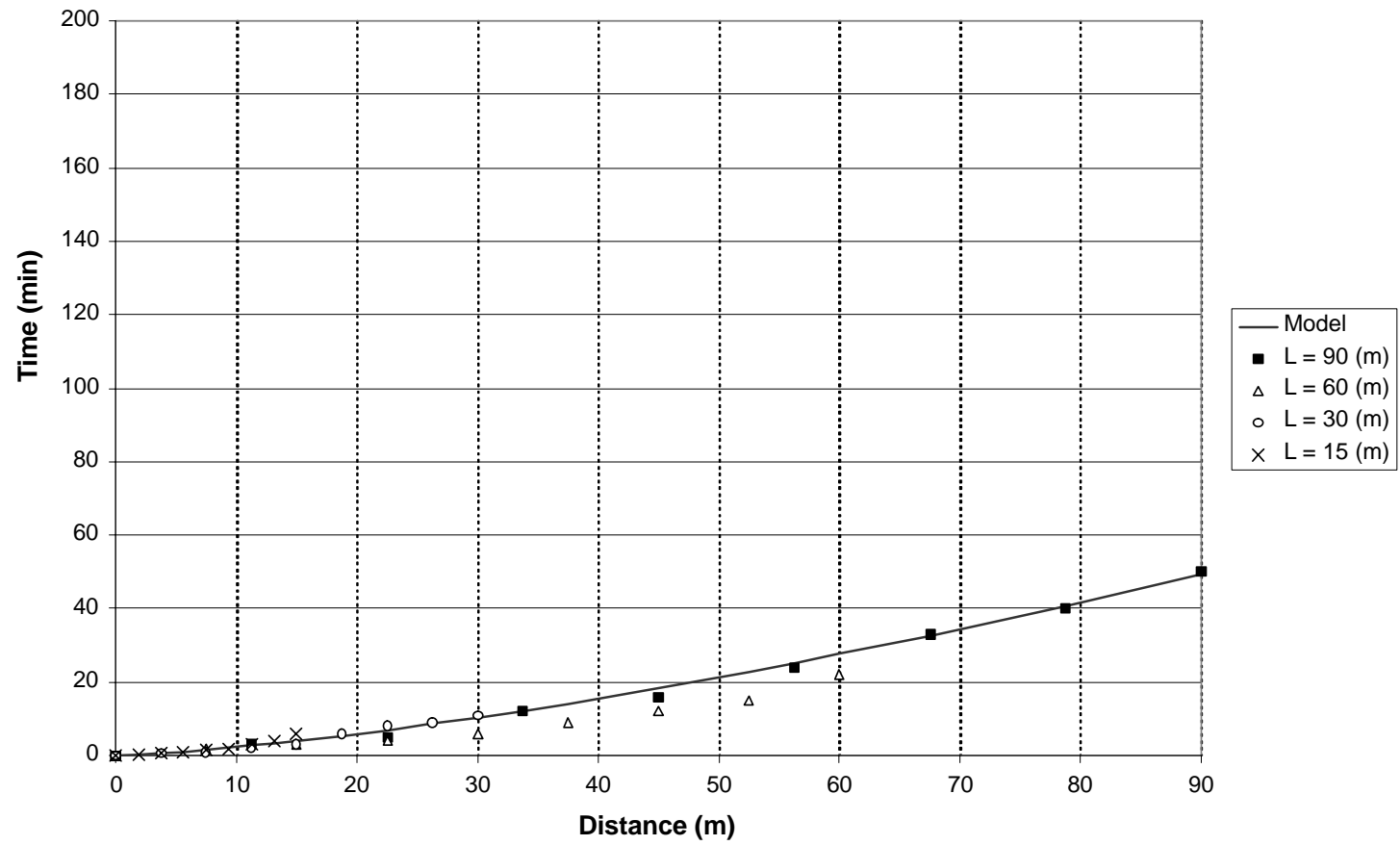

Figure 6. Distance vs. advance time for $Q=0.144 \mathrm{~m}^{3} / \mathrm{min}$ for the measured points and model prediction. 


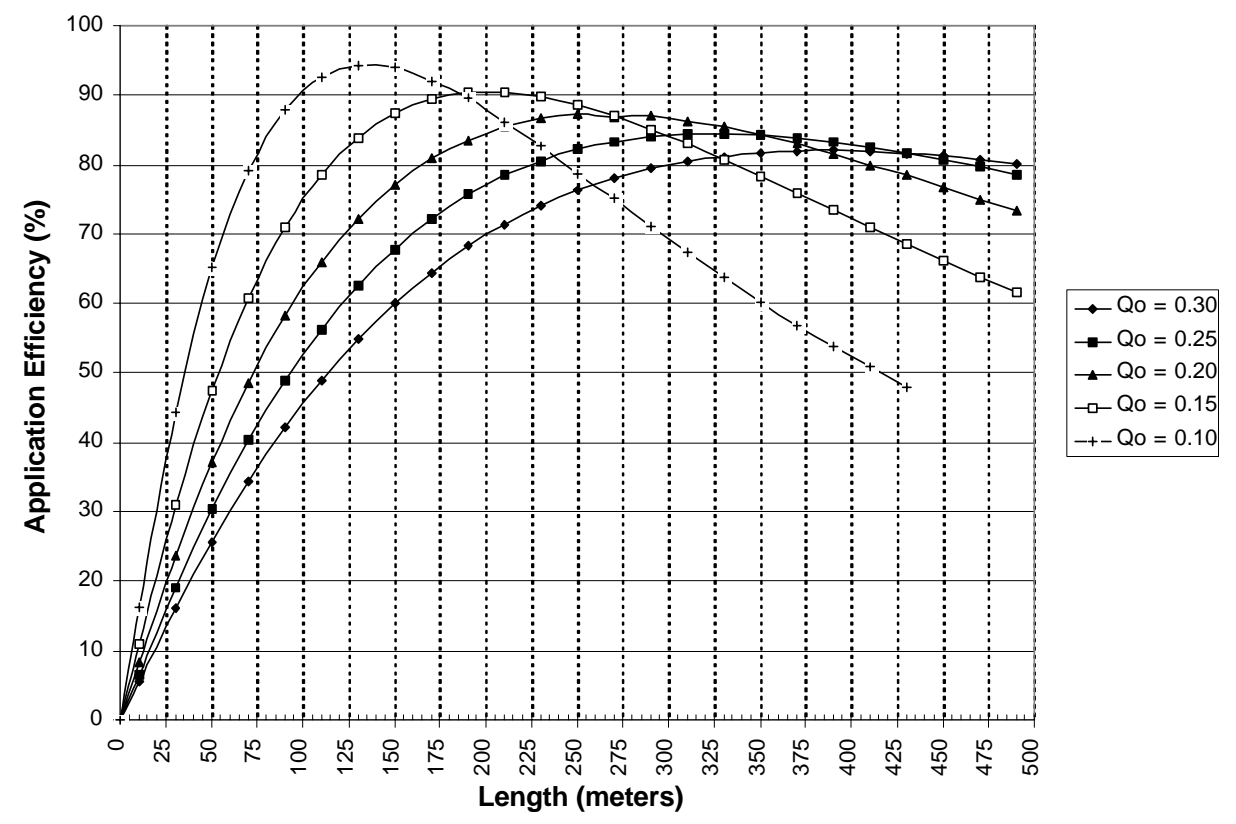

Figure 7. Furrow lengths vs. application efficiency for modeled furrow inflows.

For example, in the first case, where the furrow inflow is $0.1 \mathrm{~m}^{3} / \mathrm{min}$, it is clear that the highest efficiency occurs at a furrow length of $130 \mathrm{~m}$. As the length increases beyond $130 \mathrm{~m}$ the efficiency decreases to $48 \%$ at $430 \mathrm{~m}$. In the second case with a furrow inflow of $0.15 \mathrm{~m}^{3} / \mathrm{min}$, an efficiency of $90 \%$ is obtained with a length of $210 \mathrm{~m}$ and then the efficiency decreases to $61 \%$ at $490 \mathrm{~m}$. With a furrow inflow of $0.2 \mathrm{~m}^{3} / \mathrm{min}$, the maximum efficiency of $87 \%$ is achieved at $310 \mathrm{~m}$ while the efficiency reduces slightly to $74 \%$ at $490 \mathrm{~m}$. The fifth case, with a furrow inflow of $0.25 \mathrm{~m}^{3} / \mathrm{min}$, achieves its maximum efficiency $(84 \%)$ at $370 \mathrm{~m}$ and again reduces slightly to $78 \%$ at $490 \mathrm{~m}$. The final case further illustrates this trend with a furrow inflow of $0.3 \mathrm{~m}^{3} / \mathrm{min}$ the maximum efficiency $82 \%$ is achieved at $410 \mathrm{~m}$ and only reduces to $80 \%$ at $490 \mathrm{~m}$.
Figure 8 illustrates efficiency as a function of furrow inflow for selected furrow lengths. High efficiencies can be achieved for the 25- and 50-m furrow lengths for very small furrow inflow values. Small errors in selecting or applying selected furrow inflows can reduce efficiency with small furrow lengths due to the dramatic peak in the graph at low furrow inflows. However with a $100-\mathrm{m}$ furrow length, an efficiency above $80 \%$ can be achieved for a range of furrow inflows from 0.05 to $0.10 \mathrm{~m}^{3} / \mathrm{min}$. Longer furrow lengths generally yield a higher security factor for applying furrow inflows given the constraints of water delivery systems. Although the maximum efficiency of small furrow lengths can be higher, the overall efficiency of long furrows with less dependence on furrow inflows is probably the more practical design for most systems.

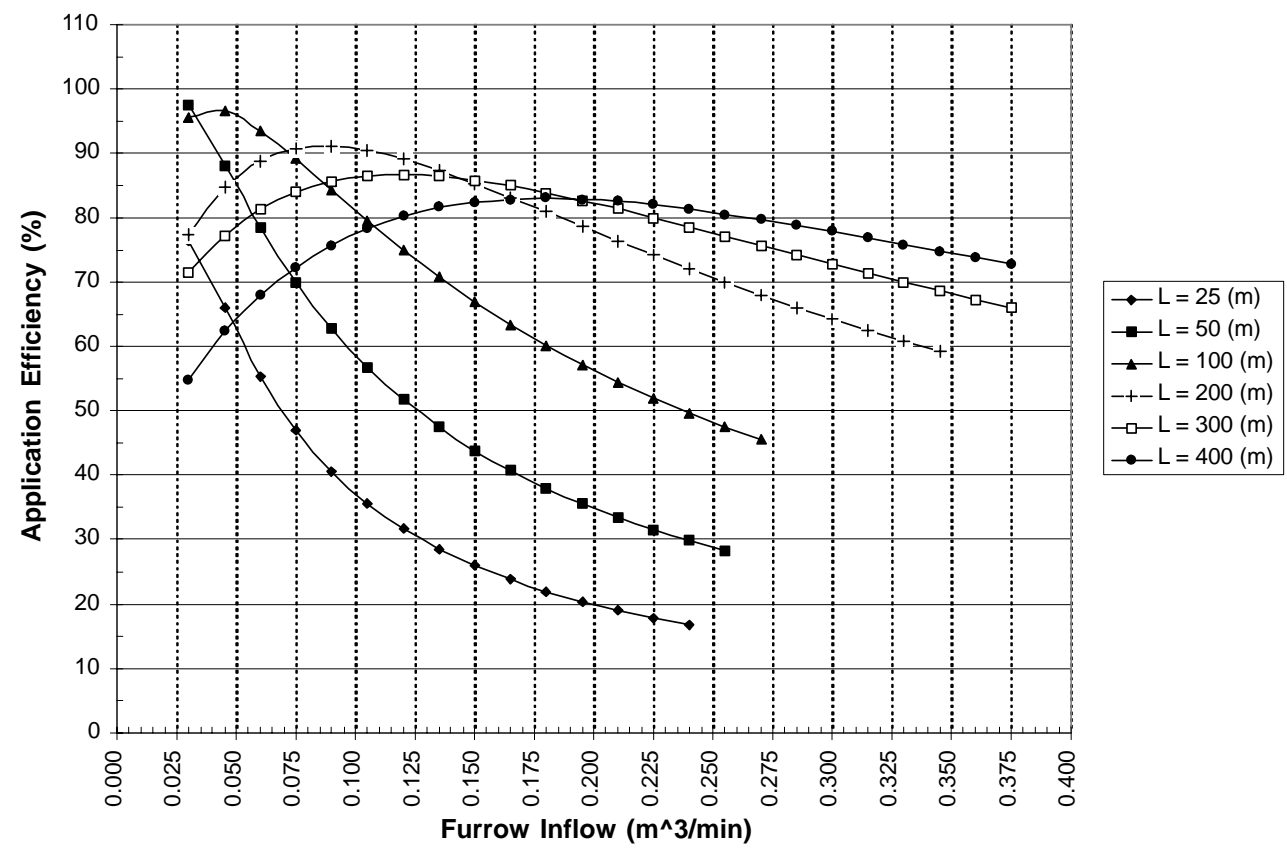

Figure 8. Furrow inflow vs. application efficiency for modeled lengths. 
Figures 7 and 8 can be used to guide farmers with similar clay soil types to select the optimal length and inflow of their furrow system. Based on the size of the field, the farmer can select which furrow inflow will produce the desired efficiency, or alternatively what furrow lengths could be used for a given furrow inflow. However as discussed previously, given a choice, higher furrow inflows and longer furrow lengths have the advantage of lower installation and maintenance costs and require less accuracy in furrow inflow application while at the same time producing only small reductions in efficiencies.

\section{Conclusions}

A common practice in Egypt and most of the developing world is to use short furrow lengths to improve application efficiencies. However, the extra effort in forming dykes and ditches and the added expense of materials for accurately applying furrow inflow amounts required for the shorter furrow lengths might not be necessary as was shown by the results of this research. In addition, with less direct intervention during irrigation applications the deformation of the furrow shape characteristics can be reduced. Tractors and pumps are now common in Egypt, however small furrow lengths are still implemented due to tradition or fear of change. As farmers begin implementing longer furrow lengths, it is important to consider the optimal application rate and feasible furrow length given ownership boundaries and/or topography.

This research shows that in clay soils relatively high efficiencies can be obtained over a wide range of furrow lengths (100 to $300 \mathrm{~m}$ ). For example, with a furrow inflow of $0.15 \mathrm{~m}^{3} / \mathrm{min}$, efficiencies between $80 \%$ and $90 \%$ can be achieved for lengths ranging from 115 to $330 \mathrm{~m}$. Longer furrow lengths should be used under these conditions since they make the irrigation system more robust. When using longer furrow lengths the irrigation system is less sensitive to variations in furrow inflow, furrow shape, field slope, and roughness. However, where longer furrow lengths are not possible, the application of water should be carefully controlled to maintain high efficiencies.

The results of this research can be summarized as follows:

- The volume balance model was satisfactorily applied for clay soils in an arid environment. The model operated well within practical design constraints.

- Furrow length and furrow inflow are the main factors affecting application efficiency for these types of soils (clay soils) with the slope and infiltration rate present at the study site.

- For clay soils, using long furrows with relatively high furrow inflows can achieve reasonable efficiencies given the constraints of installation and maintenance costs associated with shorter furrow systems.

- The use of short furrow lengths with low furrow inflows is not recommended for clay soils given the sensitivity these systems have to furrow length and inflow.

- Furrow shape is a critical parameter for determining the advance time. Consequently, design characteristics for furrow shape should be considered in installation and maintenance of furrow irrigation systems.
- The basic infiltration rate is one of the most important factors in designing a system since as the infiltration rate decreases, it is more economical to use long furrow lengths. However, this conclusion can only be made for the clay soils studied herein.

\section{REFERENCES}

Bautista, E., and W. W. Wallender. 1985. Spatial variability of infiltration in furrows. Transactions of the ASAE 28(6): 1846-1851, 1855.

Cahoon, J. E. 1995. Defining furrow cross-section. J. of Irrigation and Drainage Engineering, ASCE 121(1): 114-119.

Childs, J. L., W. W. Wallender, and J. W. Hopmans. 1993. Spatial and seasonal variation of furrow infiltration. J. of Irrigation and Drainage Engineering, ASCE 119(1): 74-90.

El-Dine, T. G., and M. M. Hosny. 2000. Field evaluation of surge and continuous flows in furrow irrigation systems. Water Resources Management 14(2): 77-87.

Fok, Y. S., and A. A. Bishop. 1965. Analysis of water advance surface irrigation. J. of Irrigation and Drainage Engineering, ASCE 91(1): 99-116.

Greminger, P. J., Y. K. Sud, and D. R. Nielson. 1985. Spatial variability of field-measured soil-water characteristics. Soil Sci. Soc. Am. J. 49: 1075-1082.

Kang, S. Z., and P. Shi, Y. H. Pan, Z. S. Liang, X. T. Hu, and J. Zhang. 2000. Soil water distribution, uniformity and water-use efficiency under alternate furrow irrigation in arid areas. Irrigation Science 19(4): 181-190.

Nielsen, D. R., J. W. Biggar, and K. T. Erh. 1973. Spatial variability of field measured soil-water properties. Hilgardia 42(7): 215-259.

Prasher, S. O., M. Singh, A. K. Maheshwari, and R. S. Clemente. 1997. Effect of spatial variability in hydraulic conductivity on water table drawdown. Transactions of the ASAE 40(2): 371-375.

Reddy, J. M., and W. Clyma. 1981a. Optimal design of border irrigation systems. J. of Irrigation and Drainage Engineering, ASCE 107(3): 1013-1042.

Reddy, J. M., and W. Clyma. 1981b. Optimal design of furrow irrigation systems. Transactions of the ASAE 24(3): 617-623.

Skogerboe, G. V. 1969. Analysis of small water management structures in irrigation distribution systems summary technical completion report. U.S. Clearinghouse for Federal Scientific and Technical Information. PB-189391. Logan, Utah: Utah State University.

Schwankl, L. J., N. S. Raghuwanshi, and W. W. Wallender. 2000. Furrow irrigation performance under spatially varying conditions. J. of Irrigation and Drainage Engineering, ASCE 126(6): 355-361.

Upadhyaya, S. K., and N. S. Raghuwanshi. 1999. Semiempirical infiltration equation for furrow irrigation systems. $J$. of Irrigation and Drainage Engineering, ASCE 125(4): 173-178.

Valiantzas, J. D. 2001a. Optimal furrow design. I: Time of advance equation. J. of Irrigation and Drainage Engineering, ASCE 127(4): 201-208.

Valiantzas, J. D. 2001b. Optimal furrow design. II: Explicit calculation of design variables. J. of Irrigation and Drainage Engineering, ASCE 127(4): 209-215.

Van Vuren, G., and A. Mastenbrock. 2000. Management types in irrigation a world-wide inventory per country. Report commissioned by the World Bank. Wageningen University, Netherlands.

Walker, W. R., and G. V. Skogerboe. 1987. Surface Irrigation Theory and Practice. Logan, Utah: Utah State University. 
Wallender, W. W., and M. Rayej. 1987. Economic optimization of furrow irrigation with uniform and non-uniform soil.

Transactions of the ASAE 33(5): 1605-1611.

Zerihun, D., J. Feyen, J. M. Reddy, and Z. Wang. 1999. Minimum cost design of furrow irrigation systems. Transactions of the ASAE 42(4): 945-955.
Zerihun, D., C. A. Sanchez, and K. L. Farrell-Poe. 2001 Analysis and design of furrow irrigation systems. J. of Irrigation and Drainage Engineering, ASCE 127(3): 161-169. 